\title{
CARACTERIZAÇÃO DOS IMPACTOS AMBIENTAIS E SOCIAIS NA EXPLORAÇÃ̈O DE ROCHAS E MINERAIS INDUSTRIAIS NO DESENVOLVIMENTO LOCAL NO MUNICÍPIO DE SUMBE (ANGOLA)
CHARACTERIZATION OF ENVIRONMENTAL AND SOCIAL IMPACTS IN THE EXPLORATION OF INDUSTRIAL ROCKS AND MINERALS IN LOCAL DEVELOPMENT IN THE MUNICIPALITY OF SUMBE (ANGOLA)

\author{
Januário Cacilda André* \\ Fidel Luis Alvarez** \\ Jose Francisco Lastra Rivero ${ }^{* * *}$
}

\begin{abstract}
RESUMO: O objectivo do trabalho é avaliar de forma preliminar a relação dos impactos ambientais e sociais da exploração de rochas e minerais industriais no desenvolvimento local do município do Sumbe. Para isso, partimos das análises das causas e da identificação dos principais elementos que impactam nas comunidades do município. A metodologia utilizada constou de revisão bibliográfica; visitas a pedreiras em plena extracção e processamento de rochas e minerais industriais; e consulta aos responsáveis, empregados e membros da comunidade por meio de entrevistas e inquéritos, para revelar as causas dos impactos ambientais e sociais e sua relação no desenvolvimento local do município do Sumbe.
\end{abstract}

Palavras-chave: Extração; Rochas minerais e industriais; Impacto ambiental e social: desenvolvimento local.

\begin{abstract}
The objective of this work is to evaluate in a preliminary way the relation of the environmental and social impacts of the exploration of rocks and industrial minerals in the local development of the municipality of Sumbe. For this, we start from the analysis of the causes and the identification of the main elements that impact the communities of the municipality. The methodology used consisted of a bibliographical review; visits to quarries in full extraction and processing of rocks and industrial minerals; and to consult with stakeholders, employees and community members through interviews and surveys to reveal the causes of environmental and social impacts and their relationship to local development in the Sumbe municipality.
\end{abstract}

Keywords: Extraction; Mineral and industrial rocks; Environmental and social impact; Local development.

\footnotetext{
* Professor Assistente. Instituto Superior de Ciências da Educação (ISCED) no Sumbe (Angola). Contato: januario1973@gmail.com

** Doutor em Ciências Sociológicas e Professor Titular da Universidade de Granma (Cuba). Contato: alvarezfideluis@gmail.com

*** Doutor em Ciências Geológica e Professor Titular da Universidade de Pinar del Río (Cuba). Contato: jlastra@upr.edu.cu
} 


\section{INTRODUÇÃO}

$\mathrm{Na}$ indústria da construção civil, a rocha é considerada como um recurso natural de um valor económico indispensável. A exploração dos recursos minerais, praticada pelo homem desde a pré-história, é um processo muito essencial para o desenvolvimento da sociedade, praticamente em vários sectores.

A mineração aparece constantemente no dia-a-dia das comunidades, desde artigos em vidro (areia) e cerâmica (argila) até as fabricação de remédios, joias, etc. Ela actua como base na maioria dos segmentos industriais, desempenhando um papel importante na economia, como geradora de empregos e desenvolvimento local.

A exploração irracional dos recursos minerais provoca a génese de forte impacto negativo ao meio ambiente, no concernente à qualidade de vida dos cidadãos e na evolução das localidades, que deveria ser mitigado através de uma restauração adequada da área afectada, tendo em consideração as pesquisas dos seguintes autores (RACK, 2011; GRATZFELD, 2004; SOTOMAYOR, 2009; GOMES, 2011).

As rochas têm possibilitado o crescimento considerável nos últimos dez anos na extracção de inertes e geraram empregos, sendo usadas amplamente por grandes produtores e exportadores mundiais de rochas ornamentais e nas construções de edifícios. As rochas provocam acumulação de detritos (areias, calhaus, lodo, etc.) nas zonas de fraco desnível do leito dos rios, especialmente na parte final e a alteração do modo de vida dos seres vivos ali existentes. (SILVA, 1998).

Segundo MATTA, para expor a rocha, tanto na lavra de matacões "devido ao fato de frequentemente eles estarem todo ou em parte soterrados" (2003: p. 23) quanto na lavra de maciços, cria-se a necessidade de decampamento ou remoção de solo, geralmente sem controlo algum, ocasionando impacto visual sobre o ambiente.

Por isso o material extraído que não tiver estrutura requerida durante a produção passa a ser considerado como escombro. Assim como toda extração dos recursos naturais, a actividade de mineração acarreta impactos ambientais 
comuns a todas as áreas submetidas a esse tipo de exploração, sendo impactos ambientais socioeconómicos benéficos ou impactos adversos, tanto no que diz respeito à exploração como na geração de resíduos.

"Para atender a demanda internacional da matéria-prima, houve uma adaptação no processo de desenvolvimento socioeconômico local. A actividade econômica transformou-se de rural e extractiva para industrial, desenvolvendo uma forma inadequada, desordenada e ilegal, sendo conduzida de maneira um tanto quanto inadequada, sem projetos preestabelecidos e ambientalmente sustentáveis, impossibilitando o cumprimento dos preceitos básicos do ecodesenvolvimento." (ALMEIDA, 2006: p. iv). Os atores locais argumentam também a urbanização do município como principal atividade de extração de rochas ornamentais para as indústrias químicas e de panela de pedra, ambas extraídas das pedreiras locais.

O rejeito da exploração das rochas ornamentais provoca impacto ambiental no solo e nos recursos hídricos. (LANGSCH; CARISSO; PEITER, 2009).

A República de Angola, na África Austral, ocupa um lugar de destaque desde o ponto de vista de recursos minerais e naturais por possuir um subsolo bastante rico. Porém, devido à falta de tecnologias e recursos humanos, ainda não é conhecida cientificamente, submetendo-se ao empirismo do seu potencial de exploração. No passado, detectou-se vários minerais valiosos no território, que está por se comprovar a viabilidade da exploração das ocorrências registradas ao longo do tempo.

Por outro lado, há déficit de conhecimento geológico do país, agravado pela quase total ausência de investigação prospectiva desde a independência, o que fomenta ampla especulação sobre a viabilidade económica financeira da extração de muitos dos recursos minerais presentes no território angolano.

Existe no país muitas evidências de acções extractivas de inertes, por falta do controle e por incumprimento das normas vigentes para a protecção ambiental. A província de Cuanza Sul não está além desta prática, situação idêntica apresentam-se no município do Sumbe, sua capital, que vem provocando graves afectações ambientais e sociais devido às acções simultâneas de empresas mineiras e grupos de pessoas não organizadas na actividade artesanal e mecanizada as que intensificam e envolvem regiões 
extensivas, dada a crescente demanda de materiais para indústria de construção civil na localidade.

No Sumbe estão identificadas sete pedreiras artesanais. A exploração Artesanal é uma actividade extractiva com uso exclusivo de métodos e meios artesanais não mecanizados e sem tecnologia industrial. A mesma consiste numa exploração mais simples de todas, isto é, constitui uma visão real do quanto é possível fazer uma luta para a sobrevivência, tendo em conta as suas consequências prejudiciais, em muitos casos, para 0 meio ambiente. (D'SOUZA, 2005; SOTOMAYOR, 2009).

"A pedra é considerada macia e por essa razão é fácil de ser trabalhada manualmente, o que explica o uso na produção dos mais variados tipos de objectos. A rocha apresenta variações de qualidade e pureza que the permitem ser usada como matéria-prima em diversos sectores da indústria." (EVANS, 2013, p.3).

Localizam-se no Sumbe nove minas ou pedreiras mecanizadas. Exploração Mecanizada é a actividade posterior à prospecção e pesquisa, abrangendo o reconhecimento, a preparação e a extracção do minério bruto, a nível do solo ou subsolo, implantando equipamentos especializados que aumentam o poder dos operadores humanos, melhorando os resultados de trabalho relativos à capacidade física humana, quando processados na própria área da mina. Os recursos geológicos são escassos e seu aproveitamento deve ser garantido com uma adequada exploração. (SOTOMAYOR, 2009).

Tudo isto mostra conhecimento insuficiente sobre as características dos problemas ambientais e sociais ligados à exploração de rochas e minerais industriais e sua influência negativa no desenvolvimento local no município do Sumbe. Em consequência, o objectivo geral do trabalho foi avaliar de forma preliminar os impactos ambientais e sociais na exploração de rochas e minerais industriais na sua relação com o desenvolvimento local no município do Sumbe. E para alcançar esse objectivo geral foram estipulados os seguintes objectivos específicos: Analisar as causas dos impactos ambientais e sociais na exploração de rochas e minerais industriais, no município do Sumbe; identificar os principais elementos impactantes presentes nessas comunidades no município de Sumbe; determinar a relação dos impactos ambientais e 
sociais na exploração de rochas e minerais industriais no desenvolvimento local.

Essa actividade, que em geral não é muito poluente em comparação com outros sectores industriais, pode gerar impactos importantes para o meio ambiente natural, em geral, e para o meio ambiente Solos em particular, se forem gerenciados correctamente em todos os seus aspectos (BLANCO, 2011, OLIVEIRA, 2006).

\section{MATERIAIS, MÉTODOS E TÉCNICAS}

Delimitação e caracterização da área de estudo

O Município do Sumbe, cuja capital é a cidade do mesmo nome, está situado ao longo da costa entre os paralelos $11^{\circ} 12^{\prime} 21^{\prime \prime S}$ e $13^{\circ} 50^{\prime} 37 " \mathrm{E}$, tem uma extensão de $5.100 \mathrm{Km}^{2}$, cerca de 267693 mil habitantes (INE, 2014).

É constituído pelas comunas de Sumbe, Ngangula, Quicombo e Gungo. Faz fronteira a Norte com o Rio Queve; a Leste com os Município da Conda, do Seles e Cubal; a Sul com o Município do Lobito e a Oeste, com o Oceano Atlântico. A área de estudo está localizada na província do Cuanza-Sul, República de Angola. (Figura nํ1).

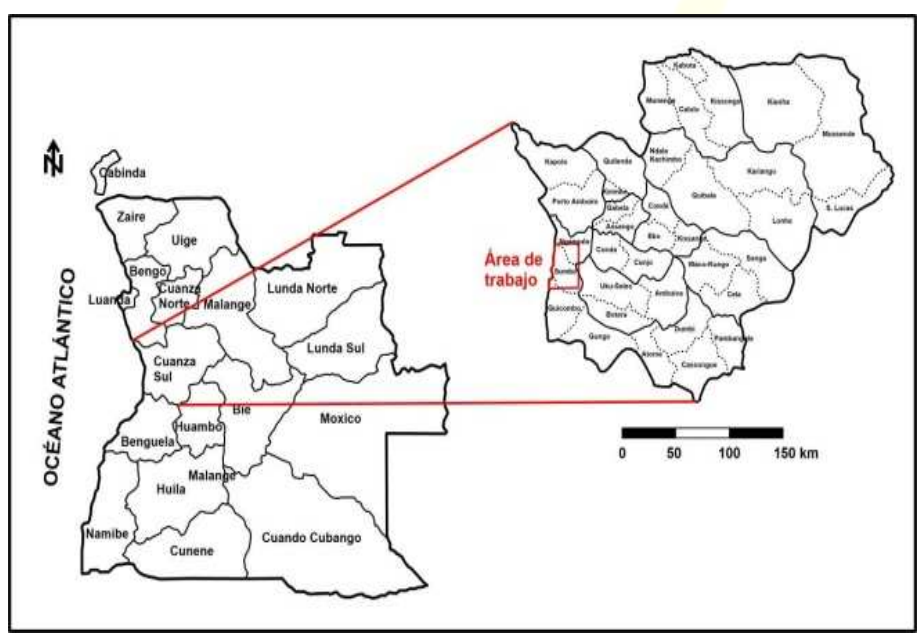

Figura $\mathrm{n}^{0}$ 1. Localização geográfica da área de estudo. Fonte: Lastra e André, 2018. 
População e amostra da investigação

O Município do Sumbe tem 16 áreas de extracção de rocha e minerais industriais, que constitui a população. Na pesquisa usa-se como mostra duas pedreiras artesanais de sete existentes e duas pedreiras mecanizadas de nove existentes (ver figura $\mathrm{n}$-2).

A escolha das pedreiras estiveram premeditadas pelos: os níveis de afectação ambiental; as proximidades as assentamentos humanos; nas proximidades dos cursos de águas com caudal permanente utilizados por os residentes; o grau de afectações sociais e as escolhas do tema foi feito pelas investigações anteriores desenvolvidas como trabalhos práticos e Trabalho de Fim de Curso opção Licenciatura em Geografia realizado com assessoria dos autores do Instituto Superior de Ciência da Educação do Sumbe. (ver figura $\mathrm{n}-2)$.

As pedreiras escolhidas da exploração artesanal são: de areias do rio Cambongo e de calcário da Pomba (Atuco). As mecanizadas são: pedreira EgiVias de calcário e a mina Super-Gesso de gesso. (ver figura nำ2 e tabela $\mathrm{n}$ ㄴ1).

Para obter a informação tubo - se presente as área de trabalho, responsáveis das mesma, mineiros, diretivos municipais e actores comunitários. (ver tabela $\mathrm{n}$-1). 


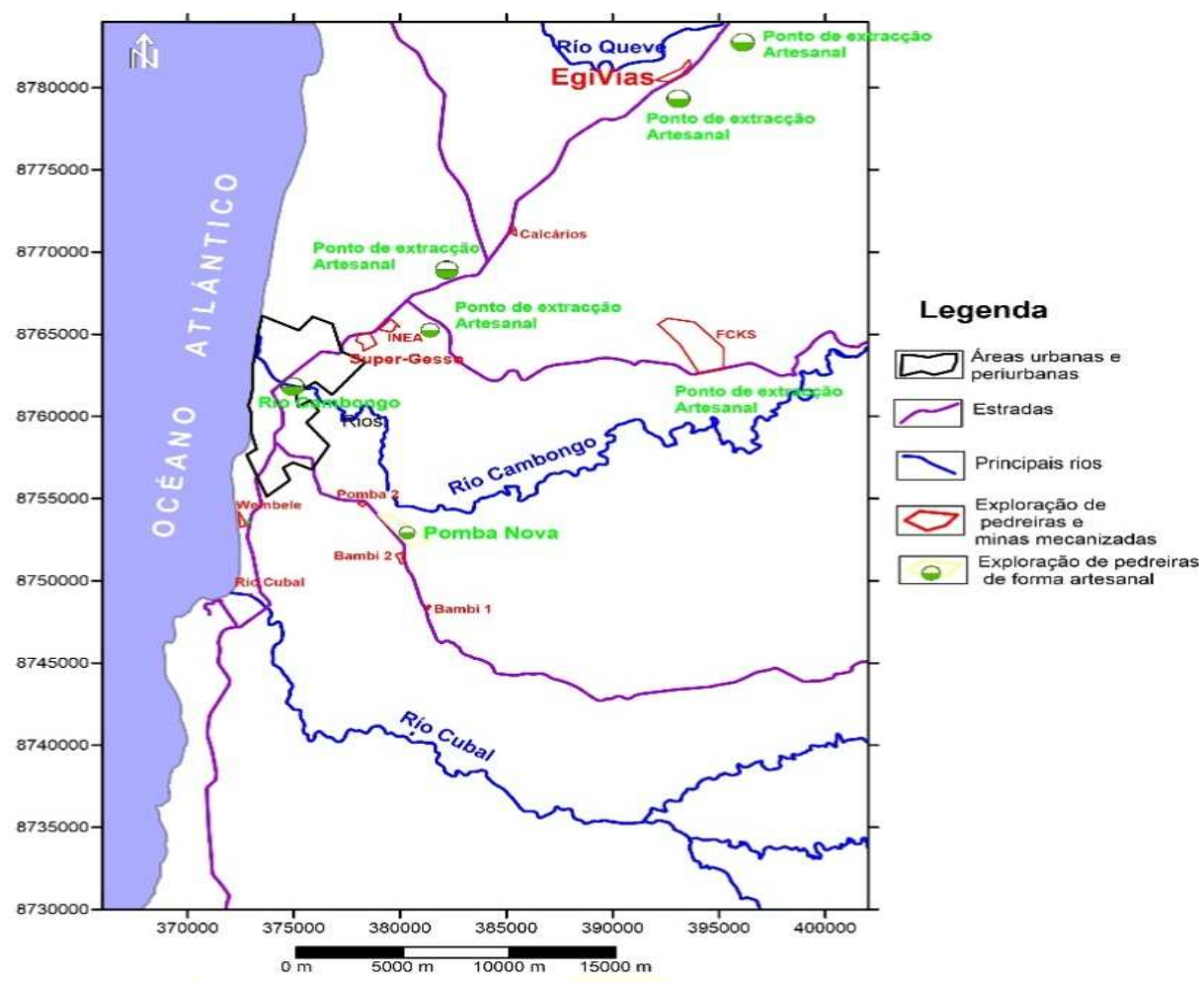

Figura ำ2. Localização de diferentes pedreiras fonte (Fonte: ALVAREZ, LASTRA e ANDRÉ, 2018)

\begin{tabular}{|c|c|c|c|c|c|c|c|c|}
\hline \multirow[t]{2}{*}{$\begin{array}{l}\text { Área de } \\
\text { trabalho }\end{array}$} & \multicolumn{2}{|c|}{$\begin{array}{l}\text { Responsáve } \\
\text { is }\end{array}$} & \multicolumn{2}{|c|}{ Mineiros } & \multicolumn{2}{|c|}{$\begin{array}{l}\text { Directivos } \\
\text { municipais }\end{array}$} & \multicolumn{2}{|c|}{$\begin{array}{l}\text { Actores } \\
\text { comunitários }\end{array}$} \\
\hline & Pop. & $\begin{array}{l}\text { Mos } \\
\text { t. }\end{array}$ & $\begin{array}{l}\text { Pop } \\
\text {. }\end{array}$ & Most. & $\begin{array}{l}\text { Pop } \\
\text {. }\end{array}$ & Most. & $\begin{array}{l}\text { Pop } \\
\text { Pop }\end{array}$ & Most. \\
\hline $\begin{array}{l}\text { Pedreira } \\
\text { Artesanal } \\
\text { Pomba } \\
\text { Nova }\end{array}$ & 2 & 1 & 44 & 24 & 2 & 1 & 56 & 20 \\
\hline $\begin{array}{l}\text { Areeiro } \\
\text { Artesanal } \\
\text { Rio } \\
\text { Cambongo }\end{array}$ & 4 & 2 & 61 & 35 & 6 & 3 & 76 & 40 \\
\hline $\begin{array}{l}\text { Pedreira } \\
\text { EgiVias } \\
\text { Mecanizad } \\
\text { a }\end{array}$ & 3 & 1 & 15 & 13 & 5 & 1 & 18 & 15 \\
\hline
\end{tabular}




\begin{tabular}{|l|l|l|l|l|l|l|l|l|}
\hline Mina & 3 & 2 & 66 & 20 & 4 & 1 & 37 & 10 \\
Super- & & & & & & & & \\
Gesso & & & & & & & & \\
Mecanizad \\
a
\end{tabular}

Tabela no1. População e amostra da investigação. Fonte: ALVAREZ e ANDRÉ, 2018.

De forma global e sintética, a formação de área sedimentar Litoral, que ocupa uma posição costeira do território angolano, é após a formação de muitos velhos sólidos (Complexo Base de Dados), rochas ígneas geralmente basaltos efusivos, basaltos, vulcanites moléculas ricas de albítico, andesite e doleritos, então rochas Pré-Cambriana representado por micaxistos e granito gneíssico - migmatito complexo, em seguida, iniciou as formações de depósito na Era Mesozóica, que se estende através das eras terciária e quaternária. Pórfiros graníticos e riólitos. A área da Pedreira da EgiVias e outras concessões caracterizam-se por calcários com substrato conglomeráticos.

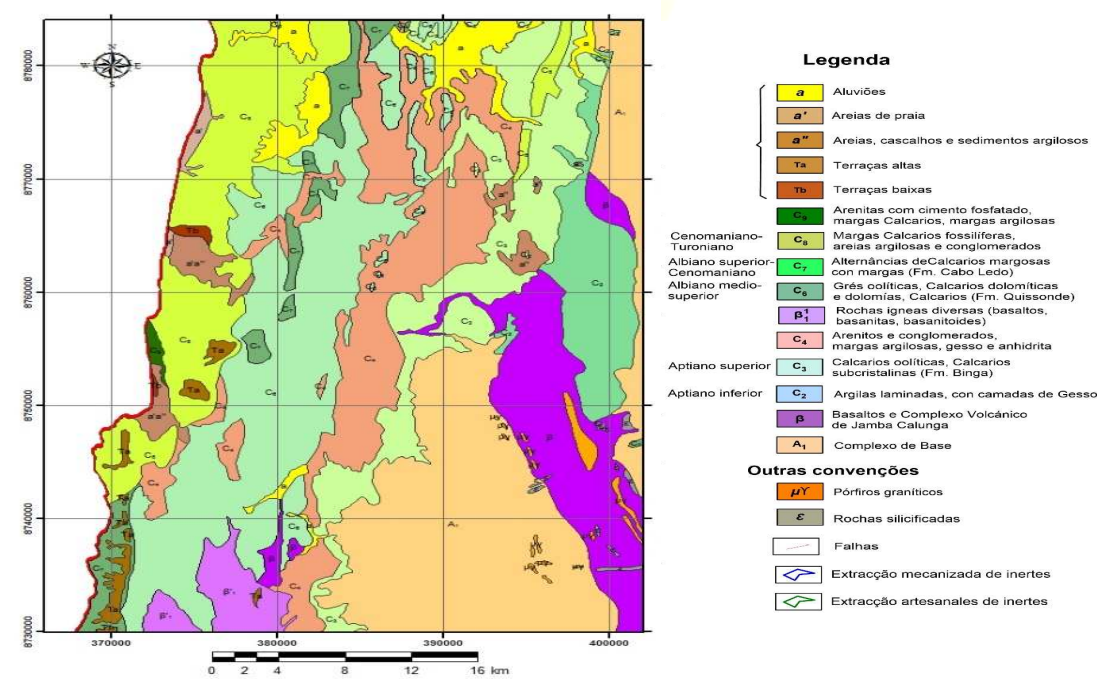

Figura 3: Mapa Geológico Escala 1:250 000. Fonte: Galvão apud por Lastra e André (2018). 


\section{MATERIAL E MÉTODOS}

Métodos do nível teórico como: Analíticos - Sínteses, Indutivo - Dedutivo e Sistémico-estrutural.

Do nível empírico: Entrevistas com responsáveis das pedreiras mecanizadas que exploram rochas e minerais industriais (Super-Gesso e EgiVias calcário). Os decisores da Direcção Provincial do Ministério da Geologia e Minas, Obras públicas e Ambiente.

Inquéritos aos empregados e autores comunitários. Também foram usados métodos de processamento de informações, como matemáticos, observação científica e modelagem.

Os procedimentos metodológicos utilizados pelos pesquisadores foram: consulta bibliográfica referente ao estado de arte através de fundamentos teóricos sobre a exploração de rochas e minerais industriais nas minas e pedreiras, assim como impactos ambientais ao longo do tempo, a nível internacional, nacional e local, resultantes dessas actividades.

Para definir as principais áreas de exploração, efetuou-se 0 levantamento preliminar, visitando todas as pedreiras - campo, com as observações objectivas e de desenvolvimento, campos de extração (SuperGesso, EgiVias, rio Cambongo e Pomba), como estudos de caso os locais mais relevantes, depósitos de tarefas do Visual / foto, o levantamento com diferentes itinerários auxiliado pelo GPS Garmin e-Trex 10, Oregon 750 para a localização e determinação das coordenadas da área, bússola, fita métrica, mapas topográficos da zona escala 1:100.000, geológicos 1:250.000, digitalizado em autoCad 2005, Surf (12\&13), Argis 10.3 e Arcmap. Assim efectuou-se o georreferenciamento, também o geoprocessamento dos dados obtidos durante a pesquisa. Neste contexto, também foram os estudantes do $4^{\circ}$ do curso de geografia que ajudaram nas recolhas de dados durante as aulas práticas integrais de campo, divididos em quatro Grupos apoiados por dois professores do Departamento de Ciências da Natureza - ISCED do Cuanza Sul. Efectuouse uma série de entrevistas aos responsáveis e mineiros envolvidos na 
extração de inertes de forma artesanal sobretudo de rochas e minerais industriais (de minas e pedreiras) e aos autores comunitários circundantes.

\section{APRESENTAÇÃO DE DADOS}

As causas dos impactos ambientais e sociais na exploração de rochas na Pedreira da Pomba Nova.

As causas dos impactos ambientais e sociais na exploração de rochas na Pedreira da Pomba Nova, Comuna do Quicombo, são resultantes da extracção do calcário provocando afectações no meio geobiofísico local sem o devido estudo de avaliação de impactos, porém dependem da consciência dos exploradores desde ponto de vista da legalidade do estado e dos exploradores particulares (ilegais).

A mineração em fragmentos das médias e baixas vertentes corrompe os atributos físicos e transgride a legislação ambiental, resultando na definição das classes geoambiental críticas.

Actualmente falta de documento de extrema valia do planeamento ambiental e ordenamento do território na localidade, nas variáveis geobiofísico e geoambiental da área da Pomba Nova, já que essa fornece dados sobre a capacidade de regulação das funções geoecológicas das paisagens segundo o grau de intervenção antrópica nos seus componentes naturais.

O diagnóstico demonstrou que a relação dos impactos evidencia que esse compreende com maior expressividade as paisagens da baixada litoral, caracterizadas por elevada fragilidade natural. Assim, tal uso é responsável pela pressão nos elementos naturais e violação na legislação ambiental, facto que implica no predomínio de paisagens com o Estado Geoambiental Crítico.

A exploração é realizada por grupos familiares permanentes, integrados por 44 mineiros todos com residência fixada na cidade do Sumbe, mas a maioria (33 mineiros) reside temporariamente durante a semana no local de exploração em condições de habitabilidade precária e outros que preferem viajar diariamente. Em geral, são pessoas com um baixo nível de escolaridade e cada grupo está composto por homens, mulheres e adolescentes. Também contratam pessoal para fazer alguns trabalhos que são remunerados precariamente. (ver figura $\mathrm{n} \cong 4$ ) 
A tecnologia utilizada consiste em instrumentos manuais e rudimentares, usados para escavar e fracturar as rochas em diferentes tamanhos mediante golpes, sendo os mais utilizados: picaretas, picos e marretas. A extracção clandestina de rochas nesta zona tem-se intensificado devido à falta de emprego e a uma grande quantidade de pessoas separadas dos seus familiares devido a limitações do desenvolvimento local.

Se manifesta uma desordem significativa dos lugares de exploração, dado pela resistência da rocha a ser fracturada. Isto determina que existam movimentos dos grupos familiares de maneira irregular até áreas onde resulte mais fácil o trabalho artesanal de extracção de rochas. Nos solos se formam buracos e ravinas, a maioria sem direcção da pendente, que se intensificam na época de chuvas devido à erosão pluvial que, por sua vez, favorecem o escorrimento superficial. (ver figura $\mathrm{n}^{\circ}$ 4)

É possível apreciar a inversão das capas dos solos nas áreas mais exploradas, que os torna improdutivos a médio prazo. Nos lugares observados onde se realiza a exploração não existem assentamentos humanos próximos, somente as habitações rústicas das pessoas que realizam este tipo de trabalho. (Ver Figura 4).

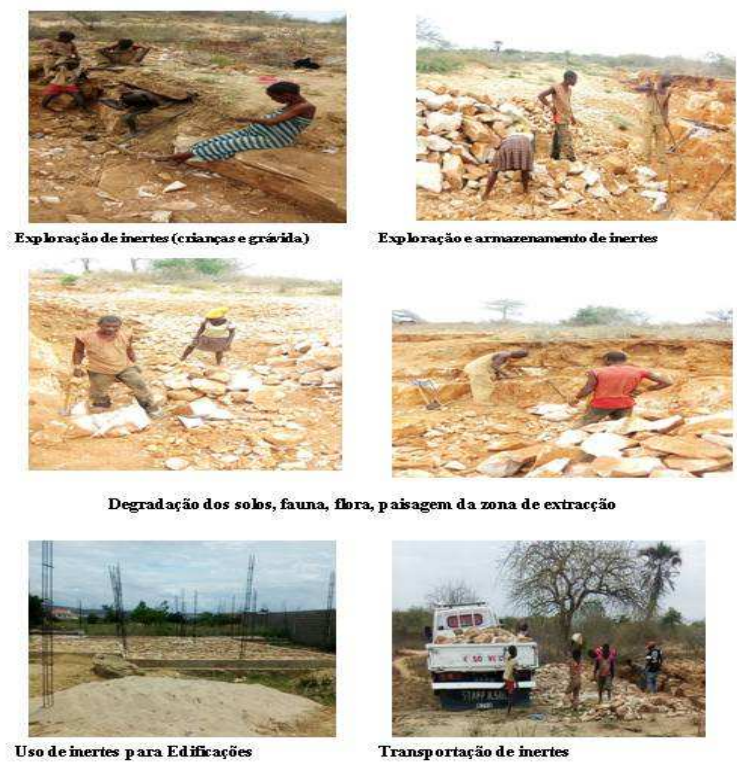

Figura no4. Panorâmica da Pedreira Artesanal Pomba Nova. Fonte. André, 2018

Não há conhecimentos que advêm dos exploradores de inertes pela via artesanal, pelo que não valorizam os impactos geoambientais, assim como as 
variáveis socioeconómicas e a população nas zonas circundantes afectados pelas consequências provocadas por diferentes impactos. A falta de estratégias de gestão ambiental que incluam os exploradores artesanais faz com que os mesmos não cumpram com o exposto na Lei de Bases do Ambiente (Lei n.o 5/98). A ausência de mecanismos de controlo estatal sobre a actividade de exploração de mineração artesanal compromete o desenvolvimento local, sobretudo na destruição do solo, da vegetação, dos habitats, da paisagem, por vezes de forma irreversível.

Tendo em conta a observação das crateras abertas nas pedreiras em estudo, permitiu propor às autoridades competentes, o uso racional e sustentável de extracção de inertes (calcário), considerando que o sector mineiro tem aberto novas perspectivas de crescimento na indústria da construção nos últimos 10 anos e porque está directamente ligado ao meio ambiente e ao desenvolvimento local, sendo capaz de explorar os recursos minerais, onde a natureza é o produto a ser comercializado. Se não for planeado correctamente poderá transformar-se num factor de destruição da biodiversidade.

As causas dos impactos ambientais e sociais na exploração de Areia no Rio Cambongo

O Rio Cambongo possui uma área de extração de areias a pequena escala e artesanal sem as exigências legais, sem as devidas licenças de todos sectores estatal das normativas da fiscalização. A actividade de extracção de areia no leito do rio torna-se ambientalmente viável desde que seja realizada de maneira sustentável atendendo as exigências estabelecidas pela legislação, além de contribuir para o desenvolvimento e harmonização da economia do município do Sumbe.

As causas dos impactos ambientais e sociais na exploração de areia no Rio Cambongo são insuficientes conhecimentos dos exploradores que extraem as areias, no leito do rio que afectam as condições ambientais; insuficiente conhecimento minera artesanal das variáveis socioeconómicas que afectam 0 ambiente assim como as consequências do seu impacto e não cumprem o que 
estabelece a Lei de Bases do Ambiente (Lei n. 5/98). $O$ antes sinalado acontece por ausência de mecanismos do controlo estatal sobre a actividade de exploração de areia no leito do rio Cambongo.

Com esta pesquisa, foram identificadas as principais variáveis ambientais afectadas, geradas por impactos da extração de areias de forma artesanal na sua paisagem visual como na geologia, geomorfologia, solo, vegetação, ar e também problemas socioeconómicos.

A extracção de areias requer, acima de tudo, princípio persistente na moral ambiental e apostar fortemente na educação, assim como na consciencialização, mas não deixando de identificar e penalizar os infratores.

Há uma evidente afectação da paisagem cujos efeitos imediatos são revelados na compactação da terra nas margens do rio, além da génese de cavidades no canal raso. Tudo isso tem um impacto directo na geomorfologia e na drenagem do rio.

Uma alta alteração na propriedade da água devido à turbidez é revelada à medida que a magnitude das partículas sólidas em suspensão aumenta, além da contribuição de outros resíduos sólidos e líquidos de origem antrópica. Isso afecta o consumo humano e animal dessas águas, além da actividade pesqueira. (ver figura $\mathrm{n}^{\circ} 5$ )

As emissões sonoras, representadas por vibrações e ruídos, afectam o meio ambiente, provocando a repulsão da fauna e desconforto aos habitantes da área circundante.

A deposição de resíduos orgânicos e a remoção de material devido à actividade extrativa causam contaminação de propriedades agrícolas e florestais próximas.

Verifica-se uma forte degradação do rio em seu canal e margens causando transbordamento que afectam os campos agrícolas, essencialmente na estação das precipitações. (ver figura $\mathrm{n}^{\circ} 5$ )

Interferência no tráfego; Acidentes de trânsito; Ausência de sinalização; Problemas de saúde e medicina ocupacional. 


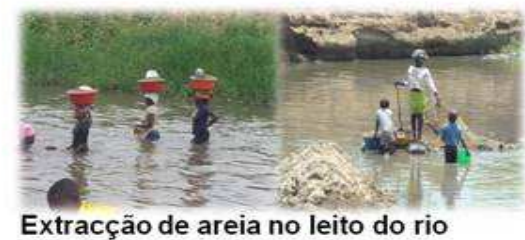

Extracção de areia no leito do rio

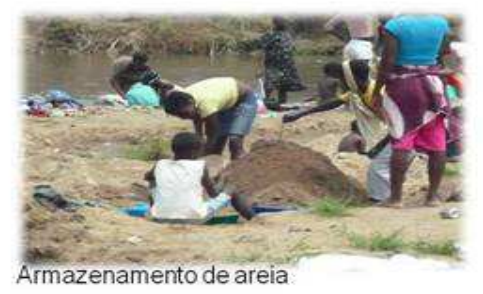

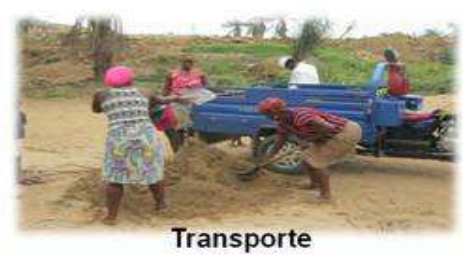

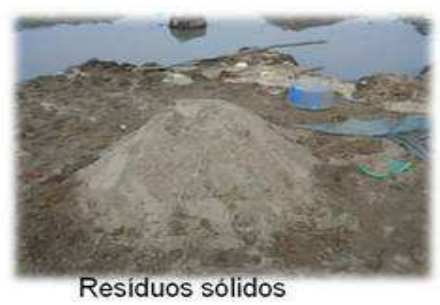

Figura ํ⒌ Panorâmica da Areeiro Artesanal Rio Cambongo. Fonte. André, 2016.

Além dos impactos negativos também geram-se a matéria-prima; Crescimento na economia local; Geração de tributos para o Estado. Essa actividade leva à geração de empregos directos e indirectos durante diferentes estágios de desenvolvimento. A demanda de areia para construção civil é satisfeita como base para o desenvolvimento socioeconômico do território. Mais renda gerada é para a comunidade; aumento nos serviços e melhoria das condições sociais.

Causas dos impactos ambientais e sociais na exploração de rochas na Pedreira Mecanizada EgiVias

Indústria localiza-se ao norte, á 30 quilómetros da cidade do Sumbe, na Comuna da Gangula. (ver figura ํㅜ6)

A pesquisa revela as causas dos impactos ambientais e sociais na exploração de rochas na Pedreira Mecanizada EgiVias construções Lda. Com esta pesquisa, foi possível identificar que são insuficientes os conhecimentos da empresa que explora os inertes pela extração mecanizada de calcários sobre os impactos resultantes dessa actividade; Insuficiente conhecimento das variáveis socioeconómicas que afectam o ambiente e a população, assim como as consequências do seu impacto; Ausência das estratégias de gestão ambiental que incluam as empresas de exploração mecanizada da rocha calcária para obtenção de seus derivados. 
Interferência no tráfego; Acidentes de trânsito; Ausência de sinalização; Problemas de saúde e medicina ocupacional. Os empregados da pedreira, trabalham $8 \mathrm{~h}$ por dia, expostos ao sol, forte quantidade de poeiras, sem qualquer protecção, propensos a doenças de pele, infeções respiratórias.

A EgiVias Construções, na sua actividade, gera os principais impactos, tais como o aumento dos processos erosivos e a destruição das formações geológica, geomorfológica, rede de drenagem, paisagem, rios subterrâneos, qualidade do ar, cobertura vegetal, remoção de solos e rochas através do uso das maquinarias pesadas durante a extracção do calcário de forma mecanizada. (ver figura $n^{\circ} 6$ )

Contudo, as áreas depressivas estão presentes em todo o planeta, de forma heterogénea, com nomenclatura diferenciada, significativa na biodiversidade, mas diante pela antropização verificam-se danos em áreas originárias e a diminuição de distintas espécies, os quais provocam impactos ambientais que comprometem as futuras gerações. (ver figura $\mathrm{n}^{\circ} 6$ )

Os empregados da pedreira da rocha calcária alegam que não há nenhuma alteração ambiental durante o processo de extracção e todos afirmam que não percebem os impactos ambientais gerados pela actividade que realizam, facto revelado durante os instrumentos aplicados.

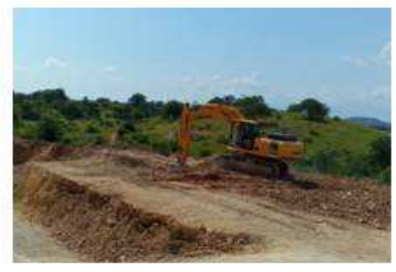

Arranque e carregamento

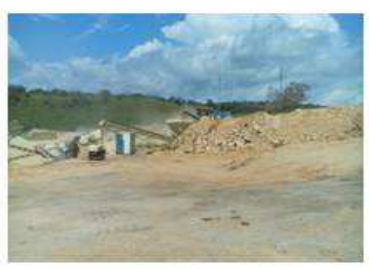

Moinho de rochas

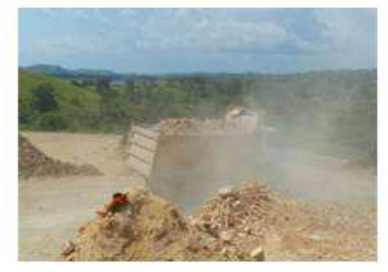

(transporte Do Calcário)

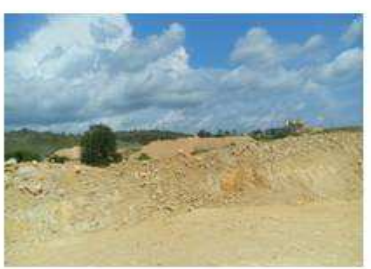

Mina e armazenamento

Figura 6. Panorâmica da Pedreira Mecanizada EgiVias. Fonte. André, 2018.

Cada indivíduo está inserido em um sistema social onde a escola seria um lugar para que desafios intelectuais fossem vivenciados e não apenas verbalizados; a formação da comunidade é essencial para promover a 
formação ecológica. É preciso que os agentes como geógrafos, geólogos e ambientalistas envolvidos neste processo, principalmente os educadores, reflictam sobre as noções do ambiente e suas inter-relações nos componentes biofísico e social, mediante a realidade actual e futura.

A empresa ignora a Lei de Bases do Ambiente (Lei n. 5/98); Inexistência de instrumentalização do controlo estatal sobre a actividade de extracção mecanizada, o que arrisca o progresso sustentável, sobretudo na destruição dos componentes ambientais da área explora da com degradação irreversível.

Mediante as visitas feitas ao local de estudo, pode-se observar que os empregados da pedreira vêm de famílias humildes, com baixas condições de habitabilidades, alegam que a remuneração não satisfaz as suas necessidades, mas trabalham de modo a tentarem suprir algumas dificuldades. Da ordem social a alimentação, transporte é precário e nível de escolaridade baixo.

Também possibilita a geração de empregos; matéria-prima; crescimento da economia local. A empresa garante alimentação, disponibilizando transportes durante a actividade laboral, optou por empregar mão-de-obra local, uma vez que a actividade não obriga a mão-de-obra qualificada, com excepção dos cooperantes que funcionam na direcção e do equipamento pesado.

As causas dos impactos ambientais e sociais na exploração de minerais industriais na Mina Super-Gesso

A Empresa Super-Gesso, localizada a 3 quilómetros da cidade do Sumbe, Alto Chingo no Controlo Norte. Existe uma mina á céu aberto para a extracção de gipsite, e processamento de diferentes produtos de Gesso, possui próprias instalações e uma fábrica.

$\mathrm{O}$ arranque efectua-se mediante perfuração e detonação a base de explosivos. $\mathrm{O}$ desperdício acumula-se numa zona adjacente à mina na ordem das 500 Ton/mês que gerou uma grande cratera que a exploração vai 
originando. Processam-se aproximadamente 10000 toneladas por mês. (ver figura 7)

O diagnóstico da empresa permitiu determinar as causas dos impactos ambientais e sociais na exploração de minerais industriais na Mina SuperGesso, as transformações geomorfológicas que como resultado da exploração do mineral a céu aberto, a extensão da área de exploração do mineral, as mudanças na vegetação existente na zona, a proximidade de assentamentos populacionais à área de exploração mineira, a localização da jazida dentro da área hidrodinâmica do Rio Cambongo e a poluição do ar pelo pó resultante da exploração do mineral e o incremento do ruído ambiental próprio da exploração a céu aberto. (ver figura 7)

Um dos instrumentos que busca estabelecer a relação entre desenvolvimento e ambiente é a Avaliação de Impacto Ambiental. Esta ferramenta permite tomar decisões acertadas, onde se procura o balanço entre o desenvolvimento económico, o uso sustentável dos recursos naturais e o bem-estar social.

Os impactos negativos causados ao meio ambiente pela exploração de gipsite pela Empresa estão pautados com a qualidade do ar, os níveis de ruído, as modificações geomorfológicas, a vegetação, a fauna, a hidrologia superficial, a paisagem e as comunidades.

Ao analisar a documentação que facilitou a empresa para a pesquisa, se pode apreciar que os estudos realizados do ponto de vista ambiental coincidem em identificar estes impactos negativos como os principais. Igualmente existe coincidência na avaliação destes impactos de natureza adversa.

Os processos erosivos também são intensificados, principalmente na estação chuvosa, o que é evidente na formação de barrancos. Transposições de horizontes do solo também são observadas, o que é altamente prejudicial ao processo normal de formação do solo.

A área produtiva permanece carecida de vegetação. A fauna está praticamente ausente devido o ruído, vibrações e outras consequências do processo produtivo. (ver figura 7) 


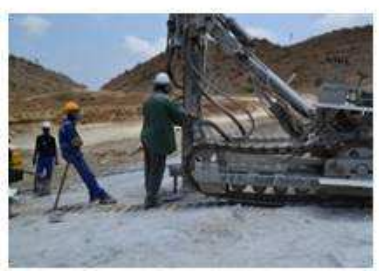

Perfuração na Mina

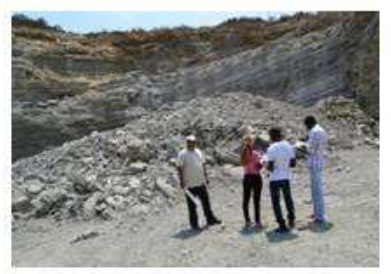

Levantamento de Dados

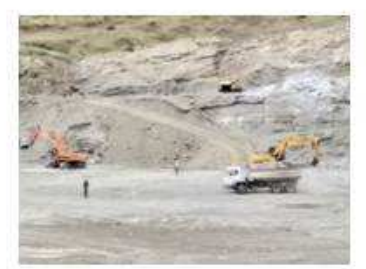

Carga e descarga (transporte)

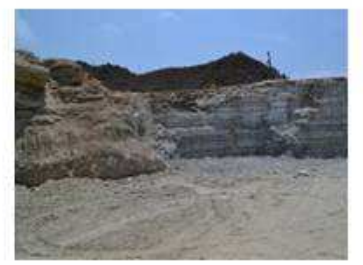

Cratera (impacto)

Figura 7. Panorâmica da Mina Mecanizada Super-Gesso. Fonte. André, 2018.

Não existe coincidência na descrição dos impactos como pouco significativos para os assentamentos humanos próximos à empresa. Entre outras razões argumentam as características morfológicas da região que servem de barreira para deter o avanço dos efeitos negativos. Não obstante os danos aos solos, vegetação e fauna têm consequências sobre outros componentes geoespaciais.

Quando se argumenta que a localidade do Sumbe não tem problemas com as reservas de água, é um facto relativo. É conhecido o grau de contaminação que possui o Rio Cambongo, que agora se incrementa com os arrastos de sedimentos provenientes da zona de exploração de mineral. A solução da água hoje não é tanto das reservas como da qualidade dessa água.

Considera-se a área ou um espaço de interesse patrimonial por estar instalado por um sistema cavernário. Encontra-se nas imediações da bacia do Rio Cambongo e esta unidade ambiental actua como um organismo vivo que precisa de todos seus componentes funcionando em perfeito estado. Se um dos componentes se afecta, produziram-se efeitos a nível irreversível na biodiversidade da localidade.

Isto significa que no espaço geográfico os componentes do mesmo não se podem analisar de forma isolada ou por segmentos e toda a natureza é patrimônio e portanto de interesse para todos os que habitamos nela.

Impactos sobre a população: Os riscos sobre a saúde e segurança se apresentarão principalmente sobre o pessoal de obra durante a execução do 
projecto, devido ao incremento dos níveis de ruído (afecções auditivas) e a emissão de gases de combustível e material particulado (afecções respiratórias) na área de extracção. As populações dispersas ao redor da empresa são testemunha de recepção de fortes impactos. (ver figura 7)

Além de os impactos negativos geram-se impactos positivos da exploração de gesso. A existência neste local cria condições para atender todas as necessidades nacionais, principalmente aquelas relacionadas à demanda deste material para a produção de cimento. Também permite abastecer o braço agrícola e desenvolver acções relacionadas à conclusão das obras. Estima-se que o aumento na taxa de exploração possa ser usado para exportação. A mina é uma fonte de emprego para a comunidade do Sumbe, gerando expectativas sobre as futuras potencialidades para o desenvolvimento socioeconómico do território.

\section{DISCUSSÕES E INTERPRETAÇÕES DE RESULTADOS}

Impactos ambientais na exploração de rochas e minerais industriais no Município de Sumbe

Segundo Brum, “... o sector mineral é considerado um dos principais causadores de degradação ambiental, principalmente em função de alterações na fisiografia (remoção do solo, supressão da vegetação, deposição de rejeitos), efeitos na qualidade e quantidade dos recursos hídricos (aumento de turbidez, assoreamento de rios, contaminação), emissão de partículas, ruído e etc." (2000, p. 12) Assim as actividades de extracção em diferentes aspectos causam problemas ambientais sérios nos componentes ambientais (físico, económico, político e social) do município do Sumbe.

Em geral, os factores da actividade de mineração que produz impactos em componentes naturais do município do Sumbe: a emissão atmosférica de resíduos sólidos, líquidos e gasosos, é emitido pelas pedreiras pesquisadas.

A emissão de ruído, vibrações e substâncias radioactivas, é outras das afectações no território. A destruição de morfologia, geologia, flora e fauna, paisagens, solos e áreas selvagens com sua diversidade genética. Poluição de recursos naturais renováveis, agricultura, silvicultura e pesca, devido à emissão de resíduos. 
Os resíduos, todos os escombros de operações de tratamento mineral e outros resíduos sólidos são galhos, folhas, lixo doméstico, lodo do sistema de tratamento de efluentes líquidos e esgoto, sucata, lâmpadas queimadas, baterias e óleos usados.

Os impactos ambientais que a mineração gera, os mais importantes e que estão presente na unidade de análises (Pedreira Artesanal de Pomba Nova - Atuco, Comuna de Quicombo. Areeiro Artesanal Rio Cambongo, Comuna de Sumbe. Pedreira Mecanizada EgiVias construções Lda. no bairro da Cassonga, comuna da Ngangula. Mina Super-Gesso, Alto Chingo, Comuna de Sumbe).

Na Geologia e Geomorfologia. Produzi - se variação da morfologia do terreno onde se explora na criação de depressões, construção de elevações artificiais ou criação de planícies pela eliminação da morfologia original e modificação do relevo, alteração da estabilidade de encostas, normalmente provoca mudanças sobre a topografia, muda os riachos desviados ou as pequenas lacunas secam e provocam efeitos diferentes sobre as características naturais da área de exploração na questão hidrodinâmicas.

No Atmosférico, a emissão de poeiras e outros gases poluentes devido à emissão de gases de combustão da maquinaria utilizada e gerando partículas de poeira, retirando a qualidade do ar.

$\mathrm{Na}$ Hidrogeologia, existe alteração da qualidade da água por partículas suspensas, da qualidade da água devido o aumento de sedimentos e de resíduos orgânicos, transformação da rede de drenagem superficial, acúmulo de água da chuva em crateras geradas, mudança no regime de escoamento e nas massas de águas interiores assim como ecossistemas aquáticas e marinhas, Além disso, a drenagem das pedreiras e poços pode mobilizar grandes volumes de sedimentos suspensos ou várias substâncias dissolvidas na água, o que prejudica a qualidade das águas subterrânea.

No solo diminuição da camada, incremento da degradação da água devido à erosão, desestabilização de encostas e aumento de deslizamento de blocos, a poluição ambiental com diferentes tipos de energia (ruído, vibração, calor, etc.) e compactação dos solos. 
Os impactos da mineração têm a ver com a própria mina, com o descarte dos resíduos da mina, com o transporte do minério e com o seu processamento, que muitas vezes envolve ou produz materiais perigosos;

$\mathrm{Na}$ Paisagem, aumenta a mudança da qualidade de fundo intrínseco e na fragilidade visual. O caso específico da extracção de rochas e minerais industriais através da exploração artesanal gera um alto impacto sobre o meio ambiente quando a restauração da área degradada.

$\mathrm{Na}$ fauna e flora, descaspe dos solos afectam o habitat da fauna e flora nas áreas exploradas, cobertura de vegetação eliminação e pressão na cobertura vegetal, geração de patologias vegetais e vida selvagem destruição do habitat (escavações e abertura de acesso), alteração do hidrobiológico e atropelamento dos animais selvagens, mudança no ciclo reprodutivo, destruição do habitat, diminuição da reprodução de espécies aquáticas.

Impactos sociais na exploração de rochas e minerais industriais no Município de Sumbe

Esta actividade representa um contributo significativo e necessário para o desenvolvimento socioeconómico do município e é uma fonte de emprego e inclusão para um sector importante da população desfavorecida que precisa de ajuda. O conhecimento técnico das pessoas envolvidas na extração e comercialização das areias é insuficiente, bem como suas consequências para o meio ambiente. Não existem regulamentos que permitam a organização, regulação e supervisão da gestão ambiental, desde a incorporação de pessoas físicas à prática desta actividade tradicional.

O que suporta a necessidade de "um desenvolvimento que satisfaça as necessidades do presente sem pôr em perigo a capacidade das gerações futuras para atender suas próprias necessidades”. (ONU, 1987)

O campo da saúde ambiental ainda ocupa um papel marginal na pesquisa das questões ambientais. O quadro vigente de fortes impactos à saúde causados pelas questões ambientais impõe a necessidade de se avançar quantitativa e qualitativamente na produção científica da saúde colectiva, sendo particularmente urgente no que se refere às ciências 
ambientais e sociais. Os resultados antes expostos permitem assinalar os impactos sociais na exploração de rochas e minerais industriais no município do Sumbe.

Vinculam-se as necessidades sociais do uso de rochas e minerais industriais, o desenvolvimento urbano requer grandes quantidades de materiais geológicos para a construção, pavimentação, preenchimento de depressões da superfície, entre outros. Em cada espaço urbano pode haver milhares de metros cúbicos $\left(\mathrm{m}^{3}\right)$ de tijolos, blocos, cimento, rochas e outros componentes necessários para a implementação das várias estruturas que estes edifícios requerem todos estes materiais explorados são recursos não renováveis e, como tal, devem ser tratados a partir de uma exploração racional e sustentável.

No individual podem assinalar-se impactos positivos como a geração de empregos transformação da capacidade de planeamento da comunidade, evolução na dinâmica populacional, troca na oferta de bens e serviços e geração de expectativas.

A exploração dos inertes possibilitou o aumento da construção de diferentes edifícios públicos e privadas assim como infraestruturas fabril e de geração de água e energia, estradas, construção de reservatórios e estações geradoras de energia. Esta actividade representa um contributo significativo e necessário para o desenvolvimento socioeconómico do município e é uma fonte de emprego e inclusão para um sector importante da população desfavorecida que precisa de ajuda.

Mudança no meio social mais oferta e demanda de todos serviços em forma geral. Deslocamento de outras actividades económicas locais actuais e/ou futuras. Quando realizado em áreas remotas, envolve grandes obras de infraestrutura.

Geração de tributos para o Estado a medida que evolui a actividade económica e tributaria aumenta e mais arrecadação para estado melhoria dos serviços públicos como saúde, Educação e segurança.

Os impactos demográficos aumentam a migração do êxodo rural, mudança na dinâmica populacional para melhorar as condições de vida. Aumento da perigosidade da localidade.

Interferência no tráfego, aumenta os acidentes de trânsito na zona de extracção, ausência de sinalização nas vias primárias e secundárias. 
Evolui a vulnerabilidade das doenças sexuais transmissíveis, as pessoas que trabalham nessas actividades de mineração sofrem de doenças graves entre os quais incluem: problemas respiratórios e reprodutivos, a silicose, a tuberculose, leucemia e gastrite.

Gera desintegração social, alteração das relações sociais aumenta a exploração sexual e uso estupefacientes, mudanças radicais e abruptas nas culturas regionais.

Apropriação de terras de comunidades local, distracção das formas de sustento e vida das comunidades, perda do valor arqueológica de herança de pequenas cavernas.

A necessidade de substituir as importações em detrimento da exploração de rochas e minerais industriais nos países em desenvolvimento é um estímulo para seus mercados internos. O desenvolvimento sustentável requer a promoção de valores que estimulem padrões de consumo dentro dos limites ecologicamente possíveis, e aos quais todos possam razoavelmente aspirar, implica também que as sociedades satisfaçam as necessidades humanas aumentando o potencial produtivo e assegurar a igualdade de oportunidades para todos e não deve pôr em perigo os sistemas naturais que são a base da vida na Terra: a atmosfera, os solos, as águas e os seres vivos.

O desenvolvimento sustentável pode ser dividido em três partes: ecológico, económico e social. Essas dimensões estão intimamente relacionadas e exigem um equilíbrio que possibilite a exploração racional dos recursos naturais com um mínimo de efeitos ambientais e benefícios sociais progressivos.

$\mathrm{Na}$ Sustentabilidade ambiental da extração de rochas e minerais industriais, a mineração tem uma imagem de gerar actividade com fortes impactos ambientais; bem ganhou má reputação porque até tempos muito recentes o conceito de sustentabilidade ambiental não encontrou um lugar nas abordagens estratégicas das empresas de mineração.

O desenvolvimento sustentável é sobre como aprender a valorizar, manter e desenvolver o patrimônio ambiental (ou capital natural) de tal forma que possa viver de sua renda e não de seu capital. O desenvolvimento sustentável é vinculado ao desenvolvimento local e comunitário. Para ALVAREZ, (2016) paralelamente, tem havido um interessante movimento de 
interação entre desenvolvimento sustentável e 0 comunitário e desenvolvimento local, tendendo a acordar sobre métodos, procedimentos e instrumentos de pesquisa usados na colecta de informações actuais, o uso de técnicas participativas na motivação, apresentação e construção colectiva do conhecimento, territórios objectos de investigações que variam de acordo com o conceitos de bairro, comunidade, localidade, activar de forma indistinta, em correspondência com os objectivos pretendidos, as forças endógenas para a transformação participativa de seu ambiente imediato.

A combinação dos conceitos nas localidades objecto de estudo permite aproveitar as potencialidades dos líderes comunitários (autoridades tradicionais, administradores, lideres religiosos, organizações no governamentais e líderes naturais) e as naturais para o desenvolvimento local e que fique sustentável no tempo.

Em qualquer caso, as empresas devem assumir a necessidade de realizar uma gestão sustentável de mineração, com planos de manejo que levem em conta os objectivos de uma adequada evolução ambiental da actividade extractivista.

Para a exploração sustentável desses recursos minerais e que tribute no desenvolvimento local do município Sumbe, é necessário: A implementação de regulamentos que restrinjam a extracção excessiva de minerais. A disponibilidade de tecnologias e equipamentos menos poluentes. Um planeamento adequado da ordenação ambiental e do território. Que os novos projectos de mineração levem em conta os aspectos ambientais. Que as investigações de mineração geológica sejam realizadas com alto rigor e qualidade técnico-científica.

As regulamentações e acções de conservação acabam sendo instrumentos ineficazes, dada a percepção de impunidade, decorrente do descumprimento desses regulamentos, do controle insuficiente e da não implementação das áreas protegidas. Conflitos de interesse e usos são frequentemente registrados devido à ausência de planeamento ou a ocorrência de falta de visão sectorial do planeamento do território.

O grupo de espertos consultados oferece uma série de recomendações na hora de administrar uma exploração mineira de superfície e de recuperar 
posteriormente a zona. (segundo FERNÁNDEZ, 2006) São estas recomendações aplicáveis no contexto do município Sumbe:

Extracção selectiva dos materiais e uso de redes de drenagem e depuração de vertidos.Reutilização dos escombros, que podem ser aproveitados como material como préstimo para o uso público ou privadapara estradas e outras áreas por exemplo nas depressões criadas, nos concretos, materiais cerâmicos; fonte de energia no caso do carvão; como fertilizante para a agricultura; ou como elemento para restaurar solos degradados.

Recuperação do terreno, preenchendo a cavidade mineira utilizando os escombros. Quando isto não é possível, utiliza-se a denominada mineração de transferência, que recupera uma zona da jazida mediante os materiais que se extraem em outra zona do mesmo material.

Em muitos lugares do planeta a manutenção dos diques de contenção de resíduos, escombro e lodos, com o que se podem evitar catástrofes ecológicas. Tratamento dos terrenos favorecendo a formação de ravinas, usando lodos ricos em nutrientes, ou acrescentando calcário para neutralizar a acidificação já que no Sumbe existe solos que necessita este tipo de tratamento na qual, procede-se à introdução de espécies vegetais.

Após a caracterização de impactos ambientais nas áreas dos empreendimentos, foram apresentadas as medidas de controlo ambiental e as acções de monitoramento que visa controlar e acompanhar de maneira contínua os impactos ocasionados pela extração em minas, pedreiras e áreas de extracção artesanal, devem instrumentalizar-se em prática e contribuirá de forma considerável na evolução sustentável, melhorando a qualidade de vida e ambiental das comunidades e ao desenvolvimento local do município Sumbe.

As Acções para mitigação de Impactos Ambientais, olha - se na regeneração da paisagem nas áreas abandonadas da pedreira, nivelamento da terra, reflorestamento, restauração da rede de drenagem superficial, etc. Mitigação de processos erosivos derivados de actividades antrópicas, Avaliação ambiental dos efeitos que ocorreriam como resultado da intensificação da exploração da gipsite, Adopção de medidas para minimizar o efeito dos ventos na dispersão de poeira para as populações vizinhas, Aumento e exigência no uso de equipamentos de protecção pelos 
trabalhadores, Atenção às doenças ocupacionais dos trabalhadores expostos mais directamente a poeira.

\section{CONCLUSÕES}

1. As causas dos impactos ambientais e sociais na exploração de rochas e minerais industriais, no município de Sumbe são: Ausência do estudo de avaliação de impactos. Os insuficientes conhecimentos dos exploradores artesanais e mecanizado. Insuficiente conhecimento das consequências do seu impacto. Desconhecimento da Lei de Base do Meio Ambiente. Ausência de mecanismos do controlo estatal sobre a actividade de exploração de areia, rocha e minerais. Ausência das estratégias de gestão ambiental que incluam a exploração artesanal e mecanizada. Proximidade de assentamentos populacionais à área de exploração mineira. Localização da jazida dentro da área hidrodinâmica do Rio Cambongo.

2. Determinou-se os principais impactos ambientais presentes nessas comunidades no município de Sumbe, podem agrupar-se nos positivos e negativos para o desenvolvimento sustentável local do município.

3. A relação dos impactos ambientais e sociais na extracção de rochas e minerais industriais torna-se muito importante enquanto existe esta necessidade para evolução das infra-estruturas e edifícios residências que clama o município do Sumbe.

4. A Caracterização dos impactos ambientais e sociais na exploração de rochas e minerais industriais na sua relação com o desenvolvimento local no município de Sumbe foi feita por meio da avaliação de forma preliminar dos impactos ambientais e sociais na exploração de rochas e minerais industriais na sua relação com o desenvolvimento local no município de Sumbe e a avaliação fui feita através das análises das causas dos impactos ambientais e sociais da exploração de areia, rochas e minerais; a determinação de impactos ambientais e sociais e sua relação no desenvolvimento local. 
AGRADECIMENTOS: A presente investigação traduz um processo longo de pesquisa Caracterização dos impactos ambientais e sociais na exploração de rochas e minerais industriais na sua relação com o desenvolvimento local no município de Sumbe, Angola e trabalho, de avanços, mas também de recuos. Soa terminação não seria possível sem os apoios do Ministério da Industria e Geologia e Minas, IGCA, Ministério do Ambiente e Urbanismo de Empresa Super-Gesso. Lda, EgiVias Construções. Lda., Sociedade Euyolo. Lda., assim como os seus directivos e empregados na sua incansável colaboração permanente também extensiva as áreas de extracção de forma artesanal do Rio Cambongo e Pomba (Atuco). Quero agradecer-lhes, muito para além do que estas palavras me permitem. Aos pares revisores do manuscrito pela sua dedicação no espírito crítico e de sugestões. À revista por nos conceder a oportunidade de apresentar o presente manuscrito.

\section{REFERÊNCIAS}

ALMEIDA, Suzana de. Lavra, artesanato e mercado do estatito de Santa Rita de Ouro Preto. 138 f. Dissertação (Mestrado em Engenharia de Minas) Universidade Federal de Ouro Preto, 2006.

ALVAREZ, F.; MESA, J.; TROCHE, M. A dimensão cultural do desenvolvimento local: uma experiência de aproveitar seu potencial no leste de Cuba. Berlim: OmniScriptum, 2016.

BLANCO-FERNÁNDEZ, D.; PARDO-FABREGAT, F.; MESEGUER-COSTA, S.; SANFELIU-MONTOLIO, T.; GALLARDO-IZQUIERDO. Restauração de uma pedreira de rochas industriais e minerais através de mudanças no uso: Aterro Extrativista de Resíduos de Construção e Demolição (RCD) - Forestal. 2011.

BRUM, I. A. S. Recuperação de áreas degradadas pela mineração. $22 \mathrm{f}$. Monografia (Especialização em Gerenciamento e Tecnologias Ambientais na Indústria) - Escola Politécnica, Universidade Federal da Bahia, 2000.

DIARIO DA REPUBLICA DE ANGOLA. Lei $n .5 / 98$. De Bases do Ambiente. I Série - N.ำ 27. 19 de Junho de 1998.

D'SOUZA, K. P. C. J. Mineração artesanal e de pequena escala na África: a relação pobre. Operações Minerais Sustentáveis no Mundo em Desenvolvimento. Londres: Geological Society, Special Publicações, 2005.

EVANS, Luciane Evans. Riquezas que vêm do pó: pesquisadores transformam restos de pedra sabão em matéria-prima. EM Notícias, Belo Horizonte, 25 maio 2013.

GOMES, S.F. Avaliação de impacto de apanha e extracção de inertes na Ribeira da Barca - Ilha de Santiago - Cabo Verde. 82 f. Dissertação 
(Mestrado em Arquitectura Paisagista) - Universidade Técnica de Lisboa, Lisboa, 2011.

GRATZFELD, J. Indústrias extrativas em zonas áridas e semiáridas: planejamento e gestão ambiental. Trad. José M. Blanch e Delmar Blasco. IUCN: Gland, Suíça e Cambridge, Reino Unido, 2004.

LANGSCH, J. E.; CARRISSO, R. C. C.; PEITER, C. C. Tratamento do efluente proveniente do corte de rochas ornamentais. Encontro Nacional de Tratamento de Minérios e Metalurgia Extrativa, 23, 2009, Gramado/RS. Anais... Porto Alegre: 2009. p. 65-70.

MARTINS, E. Impacto ambiental na exploração de pedreiras: contribuição para uma prática sustentável. 138 f. Dissertação (Mestrado) - Faculdade de Ciências, Universidade do Porto, 2006.

MATTA, P. M. Indústria de rochas ornamentais: Resíduos x Produção Limpa. Bahia: Departamento Nacional de Produção Mineral - BNPM. Salvador, 2003.

RACK, M.; OCAMPO, S. M.; CASTRO, I.; VALENZUELA, M. F. Revelação preliminar do estado ambiental atual das pedreiras agregadas em Comodoro Rivadavia. Parágrafos Geográficos, vol. 10, n. 1., p. 615-626, 2011.

SILVA, S. A. C. Caracterização do resíduo da serragem de blocos de granito. Estudo do potencial de aplicação na fabricação de argamassas de assentamento e de tijolos de solo-cimento. (Dissertação de Mestrado apresentada ao curso em Engenharia Ambiental) - Universidade Federal do Espírito Santo, Vitória, 1998.

SOTOMAYOR, L. C. Guia para as condições ambientais a considerar para o projeto de uma planta de extração e processamento agregado. $123 \mathrm{f}$. Tese (Doutorado em Engenharia) - Universidade Austral do Chile, 2009.

Recebido em: 11/04/2019

Aprovado em: 19/07/2019 